\title{
Spatial distribution of juvenile and adult stages of limnetic Cladocera in relation to selected environmental factors
}

\author{
Małgorzata ADAMCZUK* \\ Department of Hydrobiology, University of Life Sciences, B. Dobrzańskiego 37, 20-262 Lublin, Poland \\ *Corresponding author: malgorzata.adamczuk@up.lublin.pl
}

\begin{abstract}
Environmental factors have a varied impact on the development of juvenile and adult Cladocera, depending on their different physiological conditions and body size. The values of these factors alter spatially and temporarily, thus implying that they play a role in the spatial distribution of the pre-reproductive and potentially reproductive stages of cladocerans. The aim of the study was to determine seasonal and spatial variations in the distribution of juvenile and adult individuals of limnetic Cladocera in relation to selected physicochemical factors (temperature, conductivity, $\mathrm{pH}$, concentration of dissolved oxygen, total organic carbon, total suspended solids) and fish predation pressure (measured by Chesson's coefficient $\lambda$ ) in deep Lake Piaseczno (eastern Poland). Adult Cladocera displayed spatial distribution related to fish predation pressure. The species selectively eaten, $\mathrm{B}$. coregoni and $\mathrm{D}$. longispina, and non-selectively eaten, D. cucullata, selected the pelagic zone to exist, whereas those avoided by fish, D. brachyurum and B. longirostris, were evenly distributed in the littoral and pelagic zone. Juvenile cladocerans were strongly impacted by physico-chemical factors. Juvenile Daphnia, Diaphanosoma and $\mathrm{B}$. longirostris showed preferences to biotic zones similar to the adults but differed in their habitat choices. Juvenile and adult stages of $\mathrm{B}$. coregoni differed in their distribution, indicating that adult individuals impacted by high predation pressure alternatively modified their habitat selection. Principal component analysis (PCA) ordination showed a seasonal tendency for the spatial segregation of the cladocerans, suggesting that possible competitive interactions between the studied cladocerans may also influence their distribution patterns.
\end{abstract}

Key words: Cladocera, distribution, littoral, pelagic zone, habitat.

Received: June 2011. Accepted: September 2011.

\section{INTRODUCTION}

The relation between the time spent in the juvenile or adult stage during an individual lifespan plays an important role in cladoceran behaviour. This often results from defence strategies against vertebrate or invertebrate predation. The bulk of planktivorous fish are visual hunters selecting large and conspicuous prey (Brooks, and Dodson 1965; Zaret, and Kerfoot 1975), thus with fish predation Cladocera start to reproduce as early in their life cycle as possible, and due to the allocation of energy to reproduction, they do not grow much larger (Gliwicz et al. 2001). Most invertebrate predators locate prey by mechanoreceptors and prefer to capture small animals (Dodson 1972; De Bernardi 1974; Hovenkamp 1989). In this situation, Cladocera grow quickly and allocate energy to reproduction late to be invulnerable when they reproduce the first time. This plasticity of cladoceran life-strategies is possible due to their belonging to a small group of animals which reproduce mainly through parthenogenesis. Parthenogenetic reproduction and a strong maternal effect (Lynch, and Ennis 1983) result in cladocerans being able to generate offspring adapted to any changes that have taken place in the environment before their birth (Vonder Brink, and Vanni 1993). Although juveniles dis- play higher adaptation to the altered conditions (see Matveev, and Gabriel 1994; Hülsmann, and Weiler 2000), they are also regarded as being more sensitive to unfavourable environmental factors, e.g. crowding (Lynch 1978), starvation (Tessier et al. 1983) and UV radiation (Leech, and Williamson 2000), than adults.

Among the cladocerans there is a numerous group, mostly of the Chydoridae family, that represents a stable pattern of horizontal distribution as their occurrence is restricted to the littoral zone only. Limnetic species of Cladocera represent an ephemeral pattern of distribution, i.e. they exist in the whole of a lake but their temporal heterogeneity responds to environmental variables. Predators, when consuming zooplankton locally, deplete their numbers or induce some individuals to seek refuge, i.e. portions of the environment where predation pressure is absent or greatly diminished. Abiotic factors, such as temperature, dissolved oxygen and light, can also influence the spatial distribution of species (Lampert 1989; Wright, and Shapiro 1990). Cladocerans, due to their special role in food chains, are often studied under natural conditions, but these studies involve entire populations and do not focus on pre-reproductive and potentially reproductive stages. Thus, evidence concerning the density pattern of 
juvenile (pre-reproductive) and adult (potentially reproductive) cladocerans and their response to selected environmental factors are scarce, and the differences/ similarities in their spatial distribution have not been reported yet. The aim of the study is to compare the horizontal distribution of the juvenile and adult stages of five limnetic species of Cladocera, i.e. D. cucullata G. O. Sars, 1862, D. longispina (O. F. Müller, 1776), B. longirostris (O. F. Müller, 1785), B. coregoni Baird 1857 and $D$. brachyurum (Liévin 1848), as well as to determine the role of fish predation pressure, physico-chemical factors and habitat architecture in their distribution pattern.

\section{MATERIALS AND METHODS}

The study was conducted in mesotrophic Lake Piaseczno, situated in the eastern part of Poland. The lake area is 83.20 ha and its maximum depth reaches $38.8 \mathrm{~m}$. In the eastern part of the lake, a $390 \mathrm{~m}$ transect stretched from the shore to the deepest part of the lake was set. Samples were collected vertically on seven points located along the transect. The first four points corresponded with the littoral zone, where samples were taken among the reed Phragmites australis (point I - distance from the shore was $1 \mathrm{~m}$, depth $0.7 \mathrm{~m}$ ), in a site located above the sandy bottom without plants (point II - distance $10 \mathrm{~m}$ from the shore; depth $1.5 \mathrm{~m}$ ), among water milfoil Myriophyllum alterniflori (point III - distance $40 \mathrm{~m}$; depth $3 \mathrm{~m}$ ), and above macroalga Nitella flexilis (point IV - distance 85 $\mathrm{m}$, depth $5 \mathrm{~m}$ ). Point V (distance $135 \mathrm{~m}$, depth $7 \mathrm{~m}$ ) was placed in the sublittoral with the bottom grown with separate clusters of Drepanocladus sp. Points VI (distance $225 \mathrm{~m}$, depth $15 \mathrm{~m}$ ) and VII (distance $415 \mathrm{~m}$, depth $35 \mathrm{~m}$ ) were located in the pelagic zone. Regions along the transect were defined as: near shore (0-1 m along the transect), near littoral $(2-10 \mathrm{~m})$, deep littoral $(11-85 \mathrm{~m})$, sublittoral (86-135 m), near pelagial (136-225 m), and deep pelagial (226-415 m). If possible, the samples were taken vertically every 1-2 m of depth in every sampling point. Due to the samples being taken horizontally in sites of different spatial architecture and vertically from some depth levels, different habitats could be distinguished in the littoral. In the pelagic zone, the epilimnion, metalimnion and hypolimnion were calculated on the basis of temperature and oxygen stratification, and samples gathered in point VII were attributed to the adequate thermal layer. The densities of five species of Cladocera were monitored monthly from April to November. Zooplankton were collected around noon using a 5-L sampler. Double samples were collected and pooled to reduce heterogeneity in zooplankton distribution and sampling variability. In total, 38 samples were collected every month. Samples were sieved through a $50 \mu \mathrm{m}$ mesh net and preserved in formalin-glycerine solution. In the laboratory, the animals were classified and counted to calculate abundance ex- pressed as the number of individuals per $1 \mathrm{~m}^{3}$. In each sample, the length of thirty randomly found individuals of the examined species was measured. The proportion of juveniles and adults in the population was estimated after determining the size at maturity (Stibor, and Lampert 1993) for each of the sampling times. Simultaneously with the zooplankton sampling, the physico-chemical data (temperature, conductivity, $\mathrm{pH}$, concentration of dissolved oxygen, total organic carbon (TOC), and total suspended solids (TSS)) were measured. Fish for gut content analysis were collected by fyke nets in the littoral and gillnetts in the pelagial. Netting was carried out in May, July and October. In the laboratory, the fish were analysed for their stomach content. The Cladocera carapaces found in fish stomachs were classified to species level, counted, measured and then, based on their size, classified to juvenile and adult stage. The feeding selectivity of the fish towards the studied species of Cladocera was evaluated according to Chesson's formula (Chesson 1978). The values of the formula range were $\lambda=0$ (avoidance), $\lambda=1$ (selection), and $\lambda=0.5$ meant lack of selection.

One-way ANOVA (horizontal aspect) with post-hoc Bonferroni tests were run to determine the values of the physico-chemical factors (temperature, conductivity, $\mathrm{pH}$, concentration of dissolved oxygen, TOC, TSS) to assess their spatial variability. Correlations between the density of the two age stages of Cladocera and environmental factors in the seasonal aspect were assessed using Pearson's correlation coefficient. Significant levels for one-way ANOVA and Pearson's correlation were set at $p<0.05$. Principal component analysis (PCA), an indirect ordination method, was used to reveal variations in the abundance of Cladocera in the habitats. Tests for normality were performed on both limnological and cladoceran density data to determine if the datasets were normally distributed. When required, variables were either log-transformed.

\section{RESULTS}

Abiotic parameters - seasonal variation and impact on Cladocera

During the study period, the water temperature ranged between 4.2 and $27.0^{\circ} \mathrm{C}$, dissolved oxygen achieved $9.2 \pm 3.3 \mathrm{mg} \mathrm{L}^{-1}$, and both parameters changed significantly in the horizontal gradient. $\mathrm{pH}$ stayed near $7.5 \pm 0.2$. The mean values of conductivity were $101.2 \pm 19.4 \mu \mathrm{S} \mathrm{cm}^{-1}$, and total suspended solids (TSS) achieved $11.4 \pm 14.5 \mathrm{mg}$ $\mathrm{L}^{-1}$. Total organic carbon (TOC) with $3.4 \pm 3.7 \mathrm{mg} \mathrm{L}^{-1}$ differed horizontally.

The abundance of juvenile individuals of all the examined species correlated significantly with the temperature. The $\mathrm{pH}$ impacted the density of both juvenile and adult individuals of the two Bosmina species and juvenile Daph- 
nia. Adult Bosmina and juvenile D. cucullata also correlated with the conductivity. Juvenile and adult $B$. coregoni and juvenile $D$. brachyurum correlated with the oxygen content, whereas juvenile D. cucullata and B. longirostris, as well as adult individuals of all species showed significant correlations with the total organic carbon (Tab. 1).

\section{Predation of planktivorous fish}

The analysis of the stomach content of fish revealed that adult $B$. coregoni and adult $D$. longispina were the preferred food - the values of Chesson's coefficient $(\lambda)$ were 0.93 for $B$. coregoni and 0.71 for $D$. longispina. Chesson's coefficient for adult $D$. cucullata reached 0.34 . Adult $D$. brachyurum $(\lambda=0.015)$ and $B$. longirostris $(\lambda=0.21)$ were avoided, similarly to the juvenile stages of all the species $(\lambda=0-0.09)$.

\section{Horizontal distribution and habitat choice}

Adult individuals showed quite stable distribution during the study period as their density increased along with distance from the lake shore. In comparison to the adults, the juveniles were distributed quite randomly (Fig. 1). However, when considering every species separately, they showed various distribution. The bulk of adult D. cucullata and D. longispina selected near pelagial and deep pelagial to exist, and avoided near littoral, as in the case of D. cucullata, or near shore and near littoral as in the case of $D$. longispina. B. longirostris was quite evenly distributed along the whole profile, from April to July and then during October-November, to later gather in the near pelagial during August-September. Adult B. coregoni, although found in both biotic zones, settled the pelagic zone in much higher densities. Adult D. brachyurum occurred along the whole profile, but in the shallowest parts of the lake as well as the deep littoral they appeared in lower densities. Juvenile individuals displayed more distinct distribution than the adults. D. cucullata were spread along the whole profile during April-May. During the rest of the year they tended to gather in the sublittoral and pelagic zone. D. longispina had a distribution similar to that of $D$. cucullata, as they also gathered in the sublittoral and pelagic zone during most of the year and displayed even distribution during April-May and October-November. $B$. longirostris mainly gathered in the littoral parts in spring and autumn, and in the pelagic parts in summer. Juvenile $B$. coregoni avoided the near littoral but in the rest of the horizontal profile they occurred quite numerously. $D$. brachyurum were found along the whole profile, but their distributions seemed to be quite chaotic.

The principal component analysis of the habitats in the pelagic zone showed a clear gradient along the first axis (first two axes: $52.4 \%$ of explained variance). Juvenile $B$. longirostris and B. coregoni showed no clear preferences in their distribution, juvenile $D$. brachyurum existed mainly in the epilimnion, whereas two Daphnia species

Tab. 1. Pearson's correlation coefficients between density of juvenile and adult Cladocera and selected environmental factors.

\begin{tabular}{|c|c|c|c|c|c|}
\hline & $\begin{array}{c}\text { B. coregoni } \\
\text { Juvenile individuals }\end{array}$ & B. longirostris & D. cucullata & D. longispina & D. brachyurum \\
\hline \multirow[t]{2}{*}{ Temperature } & $r=0.37$ & $r=0.20$ & $r=0.36$ & $r=0.26$ & $r=0.59$ \\
\hline & $p=0.000$ & $p=0.017$ & $p=0.045$ & $p=0.001$ & $p=0.000$ \\
\hline \multirow[t]{2}{*}{$\mathrm{pH}$} & $r=0.37$ & $r=-0.20$ & $r=-0.17$ & $r=-0.29$ & $r=0.17$ \\
\hline & $p=0.000$ & $p=0.014$ & $p=0.036$ & $p=0.005$ & $p=0.035$ \\
\hline \multirow[t]{2}{*}{ Conductivity } & $r=-0.17$ & $r=0.04$ & $r=0.30$ & $r=-0.09$ & $r=0.10$ \\
\hline & $p=0.034$ & $p=0.629$ & $p=0.000$ & $p=0.255$ & $p=0.208$ \\
\hline \multirow[t]{2}{*}{ Oxygen content } & $r=-0.34$ & $r=0.15$ & $r=0.06$ & $r=0.16$ & $r=-0.50$ \\
\hline & $p=0.000$ & $p=0.069$ & $p=0.485$ & $p=0.056$ & $p=0.000$ \\
\hline \multirow[t]{2}{*}{ TOC } & $r=0.11$ & $r=-0.04$ & $r=-0.17$ & $r=-0.01$ & $r=-0.01$ \\
\hline & $p=0.017$ & $p=0.642$ & $p=0.036$ & $p=0.927$ & $p=0.944$ \\
\hline \multirow[t]{3}{*}{ TSS } & $r=0.12$ & $r=0.07$ & $r=0.01$ & $r=0.02$ & $r=0.06$ \\
\hline & $p=0.146$ & $p=0.378$ & $p=0.969$ & $p=0.778$ & $p=0.499$ \\
\hline & Adult individuals & & & & \\
\hline \multirow[t]{2}{*}{ Temperature } & $r=-0.12$ & $r=-0.02$ & $r=0.08$ & $r=-0.12$ & $r=-0.05$ \\
\hline & $p=0.156$ & $p=0.800$ & $p=0.360$ & $p=0.138$ & $p=0.541$ \\
\hline \multirow[t]{2}{*}{$\mathrm{pH}$} & $r=-0.37$ & $r=-0.20$ & $r=0.01$ & $r=-0.16$ & $r=-0.13$ \\
\hline & $p=0.001$ & $p=0.014$ & $p=0.924$ & $p=0.053$ & $p=0.120$ \\
\hline \multirow[t]{2}{*}{ Conductivity } & $r=0.19$ & $r=0.35$ & $r=-0.15$ & $r=-0.07$ & $r=0.13$ \\
\hline & $p=0.022$ & $p=0.000$ & $p=0.070$ & $p=0.397$ & $p=0.125$ \\
\hline \multirow[t]{2}{*}{ Oxygen content } & $r=0.32$ & $r=0.17$ & $r=0.01$ & $r=0.10$ & $r=0.17$ \\
\hline & $p=0.006$ & $p=0.034$ & $p=0.945$ & $p=0.211$ & $p=0.043$ \\
\hline \multirow[t]{2}{*}{ TOC } & $r=-0.13$ & $r=0.17$ & $r=-0.15$ & $r=0.20$ & $r=0.37$ \\
\hline & $p=0.013$ & $p=0.037$ & $p=0.045$ & $p=0.008$ & $p=0.003$ \\
\hline \multirow[t]{2}{*}{ TSS } & $r=-0.07$ & $r=-0.10$ & $r=0.15$ & $r=-0.05$ & $r=0.01$ \\
\hline & $p=0.414$ & $p=0.242$ & $p=0.063$ & $p=0.552$ & $p=0.933$ \\
\hline
\end{tabular}



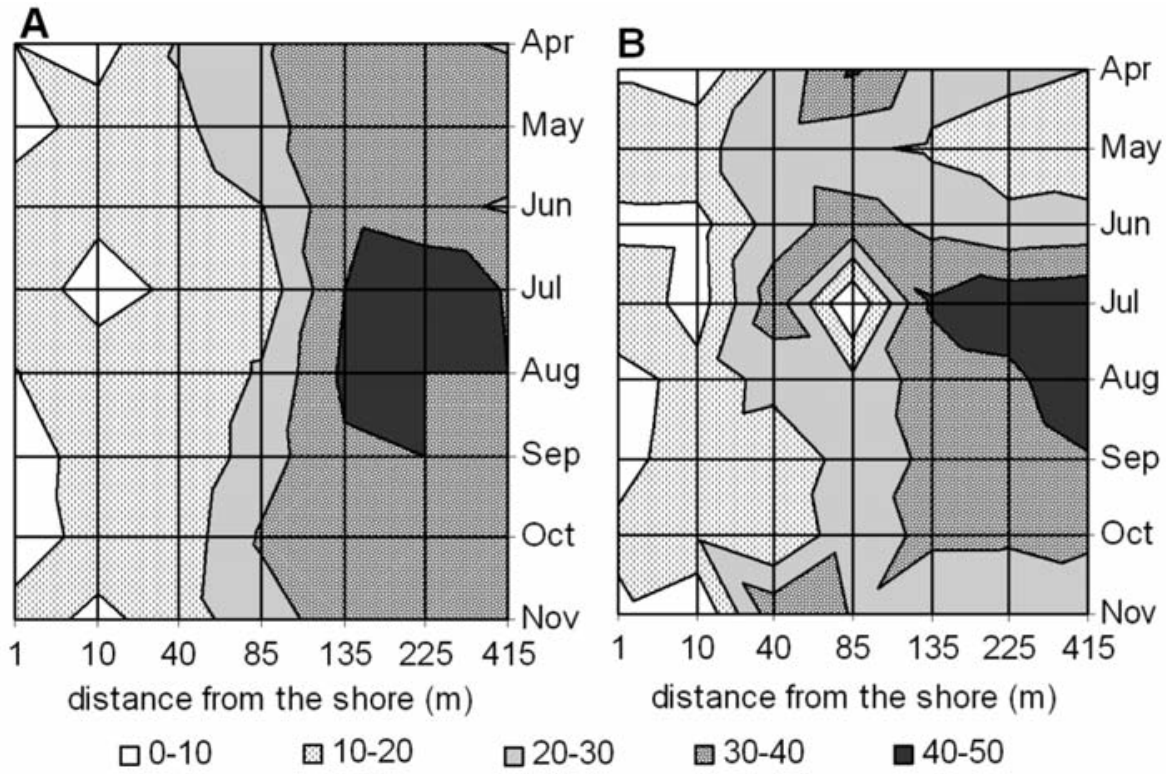

Fig. 1. The relative abundance of adult (A) and juvenile (B) Cladocera along the horizontal gradient in Lake Piaseczno.

preferred to live in the epilimnion and metalimnion. Adult $B$. longirostris were evenly distributed in all of the stratification layers. D. cucullata and D. brachyurum preferred to stay in the epilimnion, B. coregoni were found both in the epilimnion and metalimnion, and D. longispina stayed mainly in the epilimnion, but some individuals were also found in the hypolimnion (Fig. 2A). When habitats in the littoral zones were used in the PCA, a seasonal gradient occurred (first two axes: $73.5 \%$ of explained variance). Two Daphnia species and adult $B$. coregoni avoided most of the littoral habitats, occurring there more densely in early spring (April) and late autumn (November). Inversely to the adult individuals, juvenile $B$. coregoni occurred abundantly in the littoral habitats, especially during the period of intense macrophyte growth, preferring mainly water milfoil patches and shallow spaces with a sandy bottom. Juvenile $D$. brachyurum and B. longirostris showed no special preferences towards any habitats. Adult $B$. longirostris mostly selected macroalga patches to exist, whereas adult $D$. brachyurum were found amongst the water milfoil in spring and autumn, and in reed in summer (Fig. 2B).

\section{DISCUSSION}

The results obtained in Lake Piaseczno showed that age could be an important factor in determining the susceptibility of Cladocera to physical and chemical factors and to fish predation pressure. In general, most of the physico-chemical factors were more correlated with the density of juvenile than adult stages. Many studies have proved that temperature impacts the physiological processes of growth and development of Cladocera, and thus plays an important role in their seasonal dynamics (Geraldes, and Boavida 2004; Verbitskii et al. 2009). However, in the studied lake, the temperature correlated only with the density of juveniles and had no effect on the density of adults. Juvenile cladocerans are also considered to be more vulnerable to starvation than adults (Neil 1975; Lynch 1978; Tessier et al. 1983), but in Lake Piaseczno, total organic carbon influenced the density of adult Cladocera more strongly.

As the density of the juvenile stages of Cladocera in Lake Piaseczno correlated with the physico-chemical factors, adults were more subjected to fish predation pressure. Both the abiotic factors and fish predation avoidance seemed to influence the patterns of habitat choice. In the pelagial, the bulk of the adult individuals occurred in the epilimnion and metalimnion, with the exception of B. longirostris, which displayed no habitat preferences. The epi, meta- and hypolimnion in Lake Piaseczno displayed apparent vertical gradients in temperature and oxygen capacity. Some studies show that physical and chemical gradients may create natural boundaries to reduce the mortality of cladocerans (Wright, and Shapiro 1990; Bertilsson et al. 1965). The most important of these gradients is oxygen, as a concentration lower than $3 \mathrm{mg} \mathrm{L}^{-1}$ is able to restrict the downward migrations of fish grazing on cladocerans (Thiel et al. 1995). However, the minimum oxygen concentration in the pelagic zone reached higher values, so it could not have affected the vertical distribution of fish. In the littoral, adult individuals avoided stay- 

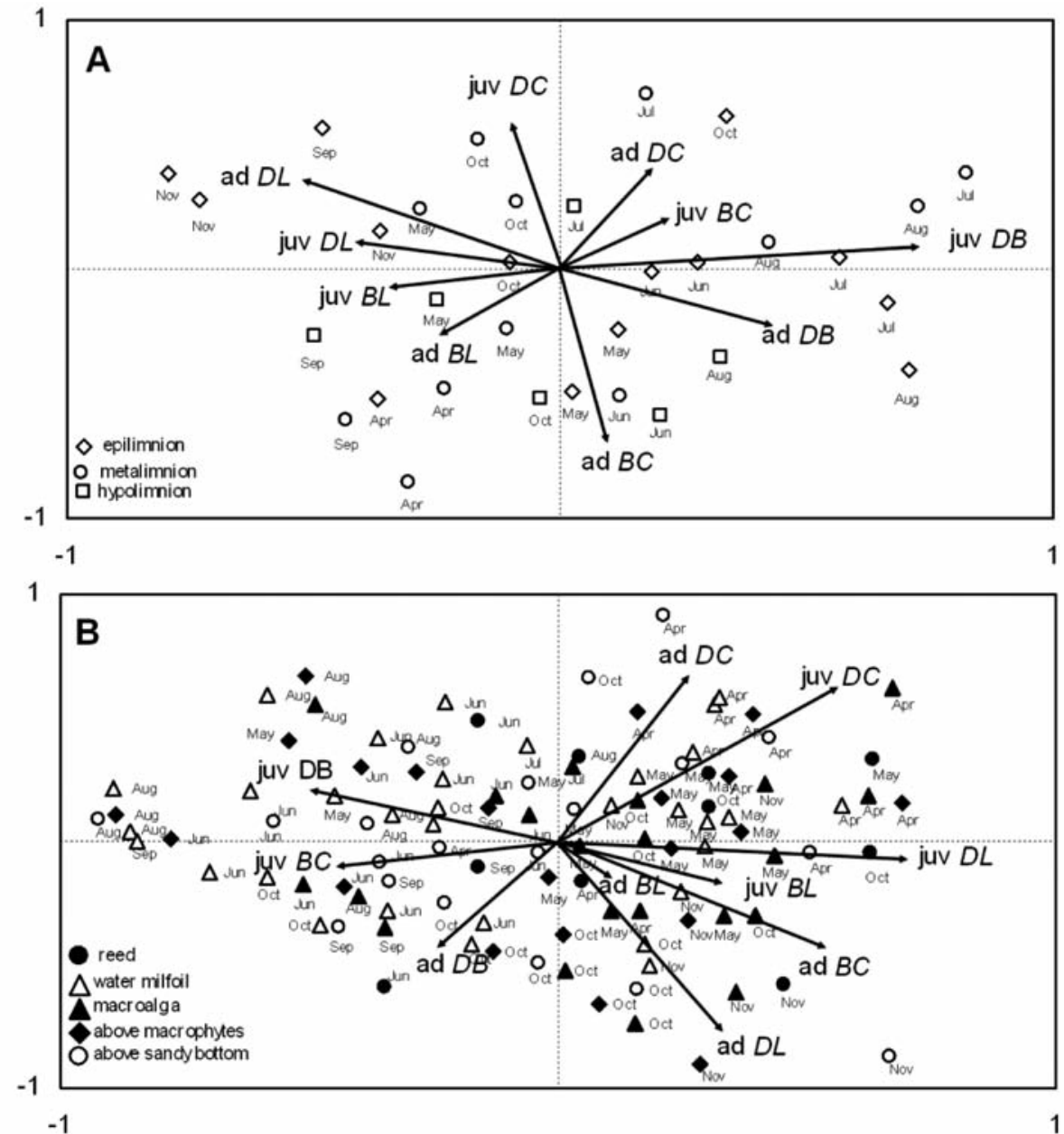

Fig. 2. PCA biplot based on adult and juvenile Cladocera assemblages sampled in the pelagic (A) and littoral (B) zones (ad = adult, juv $=$ juvenile, $\mathrm{DC}=D$. cucullata, $\mathrm{DL}=D$. longispina, $\mathrm{BC}=B$. coregoni, $\mathrm{BL}=$ B. longirostris, $\mathrm{DB}=D$. brachyurum $)$

ing within the submerged macrophytes. Submerged macrophytes are attributed to having a special role as a refuge from predation for zooplankton (Crowder, and Cooper 1982; Gotceitas, and Colgan 1989; Persson 1993; Burks et al. 2002), although food concentration for filterfeeding zooplankton is low in the plant beds, some macrophyte species may release chemical substances, and invertebrate planktivorous predator density may be high inside macrophytes (Schriver et al. 1995; Jeppesen et al. 2002). Some studies have suggested that macrophytes may selectively act as a refuge, and Jeppesen et al. (1998) encapsulated these suggestions in their alternative model by predicting that the refuge effect of macrophytes is low in hypereutrophic turbid lakes as well as in oligotrophic ones, and the highest in eutrophic clearwater lakes where there is a high abundance of submerged plants. In mesotrophic Lake Piaseczno, two age stages of Daphnia and adult $B$. coregoni avoided existence inside submerged macrophytes, so these habitats probably did not constitute refuges for them. B. longirostris, D. brachyurum and ju- venile $B$. coregoni displayed less specialisation in their habitat choice, occurring in some habitats with very similar densities. However, the submerged macrophytes also seemed to play no role as a refuge in their distribution. The results confirm the model of relations between the refuge role of submerged macrophytes and the trophic state of the lake as described by Jeppesen et al. (1998) and are consistent with those obtained by Lauridsen et al. (2001) in the Greenland lakes, where macrophytes had no impact on the distribution of limnetic species of Cladocera.

It is accepted that horizontal distribution patterns of zooplankton reflect variation in food variability and predator abundance, including both planktivorous fish and invertebrate predators (De Stasio 1993). According to the shore-avoidance theory, limnetic species of Cladocera avoid the shore parts of the lake by aggregating in the central, deeper parts (Boikova 1986; Gliwicz, and Rykowska 1992). The results obtained in Lake Piaseczno showed that adult stages of Cladocera displayed the typical pattern 
of shore-avoidance, whereas juvenile cladocerans did not show clear shore-avoidance in their distribution. Undoubtedly, adults that turned out to be less sensible to abiotic factors headed for predation avoidance and food availability in their horizontal distribution, whereas juveniles were mainly limited by changes in the physico-chemical factors.

Considering the distribution of juvenile and adult stages of 5 species of Cladocera in total, the density of the adults indeed rose along with the distance from the lake shores, whereas the density of juveniles was less ordered. However, when examining the distribution for every species and age stage separately, different patterns were distinguished. What is more, the characteristic distribution of the species suggest their temporal and spatial segregation. D. cucullata and D. longispina, irrespective of their age, mainly settled the pelagic zone and occurred in the littoral in the juvenile stage only temporarily. Daphnia avoidance of more complicated habitats is well known (e.g., Lauridsen, and Lodge 1996; Bergstrőm et al. 2000). Daphnia are often imputed the key role in water bodies due to their ability to filter particles in a wide range of sizes: from bacterioplankton to relatively large phytoplankton being able to compete with other cladoceran species because of niche overlap (Kerfoot et al. 1985). The food preferences of D. brachyurum and Daphnia species overlap almost entirely (Gliwicz 1969), thus implying processes of competitive exclusion between them (Geller, and Müller 1981). Examples of diminishing Bosmina's abundance by Daphnia through exploiting the preferred food source was described by DeMott, and Kerfoot (1982) and Vanni (1986). The case of evenly distributed $B$. longirostris is slightly different since Nillson, and Pejler (1973) found that the elimination of larger cladocerans caused littoral-restricted $B$. longirostris to spread into the pelagic zone. The littoral seems to be a "worse" zone to exist in for obligatory filter-feeders by virtue of food availability because the productivity of phytoplankton is frequently reduced there due to a weak light climate and faster sedimentation (Vuille 1991; Smiley, and Tessier 1998). Therefore, when analysing the causes of species distribution in Lake Piaseczno, it could be possible that the cladocerans grazed by fish (adult $D$. longispina, $D$. cucullata and B. coregoni) were restricted to the limnetic zone due to predation pressure and/or the species competitive to Daphnia (D. brachyurum, juvenile B. coregoni) were partly removed to the littoral zone. The shore-avoidance theory supports the first scenario, i.e. that fish predation pressure, not competition, causes the observed distribution pattern. The investigations conducted by Lauridsen et al. (2001) stated that the horizontal distribution of Bosmina sp. depends on the presence of fish. Bosmina is evenly distributed in fishless lakes, but when fish are present, Bosmina's distribution is restricted mainly to the pelagic zone. Indeed, in Lake Piaseczno adult $B$. coregoni eaten by fish prevailed in the pelagic zone, whereas $B$. longirostris and juvenile $B$. coregoni, avoided by fish, were spread both in the littoral and pelagic zone. However, supposing that competition is important when food is scarce, the low concentration of total organic carbon in Lake Piaseczno suggests that inter- and intracompetition play a substantial role in the populations of Cladocera by determining the spatial distribution and population dynamics. As was mentioned above, D. brachyurum and $B$. coregoni are often under the competition pressure of Daphnia. It is questionable if staying in the littoral zone is advantageous for the obligatorily filter-feeding $D$. brachyurum, all the more that they selected habitats with a simple architecture to exist. Inversely to Diaphanosoma, $B$. coregoni was threatened by fish predation pressure. Thus, the spatial distribution of $B$. coregoni seemed to be a tradeoff between predation avoidance and competitive exclusion by Daphnia.

The similar distribution of the juvenile and adult stages of Cladocera can be explained by phylogenetic similarity. Juvenile Daphnia, although devoid of fish predation pressure, coexisted with the adults in the pelagic zone. The juvenile and adult stages of $B$. longirostris and $D$. brachyurum, although differing in habitat choice, displayed similar horizontal distribution. Only B. coregoni varied considerably in their distribution, suggesting that the species, similarly to B. longirostris, is ecologically adapted to live in both biotic zones, and the prevalence of adult individuals in the pelagial results from shore-avoidance caused by fish predation pressure.

\section{REFERENCES}

Bergstrőm SE, Svensson JE, and Westberg E. 2000.Habitat distribution of zooplankton in relation to macrophytes in an eutrophic lake. Verh. Internat. Verein. Limnol. 27: 2861-2864.

Bertilsson J, Bērzinš B, and Pejler B. 1995. Occurrence of limnic micro-crustaceans in relation to temperature and oxygen. Hydrobiologia 299: 63-167.

Boikova OS. 1986. Horizontal distribution of crustaceans in Lake Glubokoe. Hydrobiologia 141: 113-123.

Brooks JL, and Dodson SI.1965. Predation, body-size and composition of plankton. Science 150: 28-35.

Burks RL, Lodge DM, Jeppesen E, and Lauridsen TL. 2002. Diel horizontal migration of zooplankton: costs and benefits of inhabiting the littoral. Freshwater Biol. 47: 343-365.

Chesson P. 1978. Predator-prey theory and variability. Annu. Rev. Ecol. Evol. S. 9: 323-347.

Crowder LB, and Cooper WE. 1982. Habitat structural complexity and the interaction between bluegills and their prey. Ecology 63, 1802-1813.

De Bernardi R. 1974. The dynamics of a population of Daphnia hyalina Leydig in Lago Maggiore, Northern Italy. Mem. Ist. ital. Idrobiol. 31: 221-243

DeMott WR, and Kerfoot WC. 1982. Competition among cladocerans: nature of the interaction between Bosmina and 
Daphnia. Ecology 63: 1949 - 1966.

De Stasio B. 1993. Diel vertical and horizontal migration by zooplankton: population budgets and the diurnal deficit. Bull. Mar. Sci. 53: 44-64.

Dodson SI. 1972. Mortality in a population of Daphnia rosea. Ecology 53: 1011-1023.

Geller W, and Müller H. 1981. The filtration apparatus of Cladocera: Filter mesh-sizes and their implication on food selectivity. Oecologia 49: 316-321.

Geraldes AM, and Boavida MJ. 2004. What factors affect the pelagic cladocerans of the meso-eutrophic Azibo Reservoir? Ann. Limnol. -Int. J. Lim. 40: 101-111.

Gliwicz MZ. 1969. Studies on the feeding of pelagic zooplankton in lakes with varying trophy. Ekol. Pol. Sec. A 12: 663708.

Gliwicz MZ, and Rykowska A. 1992. "Shore-avoidance" in zooplankton: a predator-induced behaviour or predator-induced mortality? J. Plankton Res. 14: 1331-1342.

Gliwicz ZM, Ślusarczyk A, and Ślusarczyk M. 2001. Life-history synchronization in a long-lifespan single-cohort Daphnia population in a fishles alpine lake. Oecologia 128: 368-378.

Gotceitas V, and Colgan P. 1987. Predator foraging success and habitat complexity: quantitative test of the threshold hypothesis. Oecologia 80: 158- 166.

Hovenkamp W. 1989. Instar-dependent mortalities of coexisting Daphnia species in lake Vechten, The Netherlands. J. Plankton Res. 11: 487-502.

Hülsmann S, and Weiler W. 2000. Adult, not juvenile mortality as a major reason for the midsummer decline of a Daphnia population. J. Plankton Res. 22: 151-168.

Jeppesen E, Lauridsen TL, Kairesalo T, Perrow M. 1998. Impact of submerged macrophytes on fish-zooplankton relationships in lakes. In: E. Jeppesem, M. Søndergaard, M. Søndergaard, and K. Christoffersen (Ed.), The structuring role of submerged macrophytes in lakes. Ecological Studies, Vol. 131, Springer Verlag: 91-115.

Jeppesen E, Søndergaard M, Søndergaard M, Christoffersen K, Jürgens K, Theil-Nielsen J, and Schlüter L. 2002. Cascading trophic interactions in the littoral zone: an enclosure experiment in shallow lake Stigsholm, Denmark. Arch. Hydrobiol. 153: 533-555.

Kerfoot WC, DeMott WR, and DeAngelis DL. 1985. Interactions among cladocerans: food limitation and exploative competition. Arch. Hydrobiol. Beih. Ergebn. Limnol. 21: 431-451.

Lampert W. 1989. The adaptive significance of diel vertical migration of zooplankton. Funct. Ecol. 3: 21-27.

Lauridsen T, Jeppesen E, Landkildehus F, and Søndergaard M. 2001. Horizontal distribution of cladocerans in arctic Greenland lakes - impact of macrophytes and fish. Hydrobiologia,442: 107-116.

Lauridsen T, and Lodge DM. 1996. Avoidance by Daphnia magna of fish and macrophytes: chemical cues and predator-mediated use of macrophyte habitat. Limnol. Oceanogr. 4: 794-798.

Leech DM, and Williamson CE. 2000. Is tolerance to ultraviolet radiation in zooplankton related to body size, taxon or lake transparency? Ecol. Appl. 10: 1530-1540.

Lynch M. 1978. Complex interactions between natural coex- ploiters - Daphnia and Ceriodaphnia. Ecology 59: 552-564.

Lynch M, and Ennis R. 1983. Resource availability, maternal effects, and longevity. Exp. Gerontol. 18: 147-165.

Matveev V, and Gabriel W. 1994. Competitive exclusion in Cladocera through elevated mortality of adults. J. Plankton Res. 16: 1083-1094.

Neil WE. 1975. Experimental studies of microcrustacean competition, community composition and efficiency of resource utilization. Ecology 56: 809-826.

Nilsson NA, and Pejler B. 1973. On the relation between fish fauna and zooplankton composition in North Swedish Lakes. Report of the Institute of Freshwater Research Drottningholm 53: 51-77.

Persson L. 1993. Predator-mediated competition in prey refuges: the importance of habitat dependent prey resources. Oikos 68: $12-22$.

Schriver P, Bøgstrand J, Jeppesen E, Søndergaard M. 1995. Impact of submerged macrophytes on fish-zooplanktonphytoplankton interactions: large-scale enclosure experiments in a shallow eutrophic lake. Freshwater Biol. 33: 255-270.

Smiley EA, and Tessier AJ. 1998. Environmental gradients and the horizontal distribution of microcrustaceans in lakes. Freshwater Biol. 39: 397-409.

Stibor H, and Lampert W. 1993. Estimating the size at maturity at field populations of Daphnia (Cladocera). Freshwater Biol., 30: 433-438.

Tessier AJ, Henry LL, Goulden CE, and Durand MW. 1983. Starvation in Daphnia: energy reserves and reproductive allocation. Limnol. Oceanogr. 28: 667-676.

Thiel R, Sepulveda A, Kafemann R, and Nellen W. 1995. Environmental factors as force structuring the fish community of the Elbe estuary. J. Fish Biol. 46: 47-69.

Vanni M. 1986. Competition in zooplankton communities: suppression of small species by Daphnia pulex. Limnol. Oceanogr. 31: 1039-1056.

Verbitskii VB, Verbitskaya TI, and Malysheva OA. 2009. Population dynamics of Daphnia longispina (O. F. Müller, 1785) and Diaphanosoma braychyurum (Lievin, 1848) (Crustacea, Cladocera) under stable and graded temperature regimes. Biology Bull. 36: 66-73.

Vanni MJ.1986. Competition in zooplankton communities: suppression of small species by Daphnia pulex. Limnol. Oceanogr. 31: 1039-1056.

Vonder Brink RH, and Vanni MH. 1993. Demographic and life history responses of the cladoceran Bosmina longirostris to variation in predator abundance. Oecologia 95: 70-80.

Vuille T. 1991. Abundance, standing crop and production of microcrustacean population (Cladocera, Copepoda) in the littoral zone of Lake Biel, Switzerland. Arch. Hydrobiol. 123: 165-185.

Wright D, and Shapiro J. 1990. Refuge availability: a key to understanding the summer disappearance of Daphnia. Freshwater Biol. 24: 43-62.

Zaret, TM, and Kerfoot WC. 1975. Fish predation on Bosmina longirostris: body size selection versus visibility selection. Ecology 56: 232-237. 